\title{
Research on the Reform of English Evaluation System in Higher Vocational Colleges
}

\author{
Wang Xin \\ Liaoning Mechatronics College, Dandong City, Liaoning Province, 118009 \\ 346591653@163.com
}

Keywords: Higher Vocational English; Multi evaluation system; Teaching reform

\begin{abstract}
The reform of Vocational English curriculum system should adapt and promote the development of talent training mode of work study combination, and one of the key points is to revise and innovate the teaching evaluation system. Based on the author's many years of work experience, this paper puts forward a multi evaluation system. The author first analyzes the present situation of the evaluation system of English Teaching in Higher Vocational colleges, then it analyzes the theoretical basis of the construction of the multiple evaluation system, finally it puts forward the implementation strategies of the multi evaluation system.
\end{abstract}

\section{Introduction}

The orientation of Vocational English curriculum emphasizes the application and Higher vocational colleges should develop a talent that can meet the needs of different social needs and changes, in order to achieve this goal, it is very necessary to reform the traditional assessment content and methods in order to explore the curriculum assessment and evaluation model which is suitable for the training mode of higher vocational education. The multiple teaching evaluation system can not only evaluate the students' course grades, but also play an important role in the cultivation of students' comprehensive ability.

\section{The Present Situation of the Evaluation System of English Teaching in Higher Vocational Colleges}

The Evaluation content is single. Due to the influence of traditional teaching concept and other factors, the evaluation of English Teaching in higher vocational colleges is still mainly in the stage of testing, and it inclined to book knowledge, ignoring the professional knowledge, safety knowledge, professional quality, professional skills and other practical knowledge content of the test. The evaluation content is relatively poor, lacks of reliability and validity evaluation, which is not conducive to individualized.

The evaluation subject is single. At present, the reform of the teaching of higher vocational education puts forward that reform should take the student as the main body, take the teacher as the leading. The administrative departments of education or teachers is the main evaluation, students are often in a passive position in the negative. The students can not play a good subjectivity, initiative and creativity. This evaluation method also ignores the importance of self - Evaluation and student evaluation in English teaching. 
The evaluation method is single. The traditional way of the examination is to adopt the unified examination question and the standard answer, which causes students to relax the usual autonomous learning, can not develop a good habit of lifelong learning, and it has a great impact on the future employment. Do not pay attention to the evaluation of students' learning process and daily behavior, and ignore the results of different learning attitudes and efforts. The evaluation methods can not meet the needs of the current situation of Higher Vocational English education.

The Evaluation tool is single. Using the final examination to assess the students' academic performance not only take the test scores as a student learning curriculum, but also make is as the standard for various awards, such as scholarship, three good student, outstanding cadres. Result is all, which makes the students just want to pass the test, and get the successful graduation and study.

The evaluation criteria is single. Too much emphasis on common and general trends ignored the value of individual differences and individual development of students. Based on the status quo of the Higher Vocational College English teaching evaluation system, cultivating students' comprehensive ability in English learning is the inevitable trend of the development of Public English Teaching in Higher Vocational Colleges.

\section{The Theoretical Basis of the Construction of the Multiple Evaluation System.}

The theory of multiple evaluation system based on the constructivism learning theory and multiple intelligence theory. Constructivism holds that students should be active constructors of knowledge meaning, rather than passive recipients of external stimuli; A teacher should be a help to construct the knowledge meaning of the students, rather than the knowledge of the person. The enlightenment to the evaluation of Higher Vocational English teaching: Not only to evaluate the student's learning results, but also to evaluate the students' learning process; The subject of teaching evaluation is not the teachers and the education authorities, but the students, as the subject of study, should be self evaluation for their own learning.

Howard Gardner's theory of multiple intelligences: Human intelligence is relatively independent of each other, and it includes language intelligence, mathematical logic intelligence, music intelligence, space intelligence, body movement intelligence, interpersonal intelligence, self understanding intelligence and natural observation intelligence and so on. The essence of the theory of multiple intelligences admits that intelligence is composed of the same important capabilities, not the one or two core competencies, admits that all kinds of intelligence is multi-dimensional, relatively independent of the performance, rather than in the way of integration. The enlightenment to the evaluation of Higher Vocational English teaching: Teaching evaluation should be diversified, not only to the students of the classroom and extracurricular learning evaluation, but also on the students learning strategies, cooperation and communication ability and so on. It should make full use of the theory of multiple intelligences to optimize the evaluation method of Higher Vocational English teaching, and promote the improvement of students' English learning ability. The multiple evaluation system of English Teaching in Higher Vocational Colleges refers to through a wide range of assessment content, assessment of the main body, assessment methods, assessment tools, evaluation criteria, a system of evaluation for students' learning outcomes and teaching process. The content of multiple evaluation includes not only the evaluation of knowledge, but also the 
evaluation of ability. The multiple evaluation subject refers to the teaching management department of teachers, students and colleges, through student self assessment, student assessment, teacher evaluation, student assessment, corporate recognition and other forms of diversity to cultivate the students' autonomous learning ability, encourage teachers to teach students in accordance with their aptitude. The multiple evaluation method refers to the diversity of assessment methods, and the multiple assessment tools refer to the various means used in the assessment, such as: classroom questions, answers, after class interviews, examinations, etc. The multiple evaluation criteria is to follow the principles of the development of students' personality and personality, and to evaluate the students' personality.

\section{The Implementation Strategies of the Multi Evaluation System}

According to the Basic Requirements of English Teaching in Higher Vocational Colleges, it needs to use constructivism theory and multiple intelligence theory as the guiding ideology of teaching evaluation, the quantitative assessment content consists Students usually score $30 \%$ (attendance $10 \%$, classroom performance $10 \%$, note $5 \%$, homework $5 \%$ ), skills assessment score $10 \%$, and the final examination results $60 \%$.

Assessment of Performance in Peacetime. The assessment of Achievement in peacetime(30\%) is mainly a formative assessment, and the valuation subjects include students and teachers, using a variety of assessment methods and diversified standards. Because this part of the assessment content is subjective, it can be divided into attendance $10 \%$, classroom performance $10 \%$, note $5 \%$, homework 5\% (in addition to the student's attendance is relatively objective). Classroom performance includes all the tasks assigned by the teacher and the English learning related tasks, the class questions and answers, group discussions, the stage of speech and performance. Note mainly refers to the two part, first, before the class is prepared, with questions to class. Second, in the class, whether to do the corresponding notes on this class heavy, difficult words, vocabulary and sentence patterns. Exercise mainly refers to the practice after class and the English topic assigned by the teacher. Master some translation skills through the practice of sentences and passages after class; Through English topic assigned by the teacher to enable students to describing personal experiences, events, perception, emotion, etc.; At the same time, according to the structure of the article, write articles related to the subject, learn to use appropriate writing skills.

In the course of English teaching, every task is evaluated immediately, written assignments to teacher evaluation, focusing on the content of the text of the discussion, speech and performance can be combined with student self-assessment, peer assessment and teacher assessment and other forms. Students' self-evaluation and mutual evaluation make them fully feel the respect and trust in their study, let them realize their own right to learn. In this way, we can see the progress of students in learning and the existence of the problem, students in the learning process to gain a sense of achievement and feedback, to stimulate greater interest in learning, learning to form a virtuous circle.

Assessment of skills assessment. Skills assessment score (10\%) is the main means of assessment students to participate in the comprehensive application of English proficiency test. Higher Vocational College English teaching should take employment as the guidance, take the practical as 
the degree of teaching idea to highlight the vocational English Service in the professional teaching, and serve the basic function of the students' employment. Therefore, the evaluation system of Higher Vocational English should also be in service to the professional teaching, according to the students' basic differences, take the B class, a class or grade three examination as a term or academic year goal. In freshman's first semester, participate in the national B level test, in the second semester, to participate in the national class A or three exams. For professional requiring a higher professional for English, we can develop other types of tests. For the professional requiring a higher writing and spoken English, for example international business, it can increase the content and requirements of the IBEC test. Through this assessment, it can stimulate students' Autonomous learning, better to apply what they have learned to practice, to achieve "learning to use", and eventually, the students' English comprehensive application ability is greatly improved.

Assessment of the final examination results. The final examination results (60\%) are mainly conducted in the way of end assessment. The examination way have a variety of forms, the combination of theory and practice, close book and volume, written and Oral Exams. The written content coverage should be broad, related to each unit learned this semester. The comprehensiveness and continuity of the examination content and the difficulty of the paper has a gradient. The examination questions including listening, reading, writing, translation, radio, etc.. In the current English final exam, even some students have some of the answers in the flash or bright spot, either take into account the standard answer, or give up their own unique point of view. In this rigid assessment, it is not objective, unfair and not rigorous performance, which directly affects the students' participation in the process of English learning and the credibility of the assessment results. Therefore, in the assessment for students' final grades, it need to increase the oral form and use the book form to make up for the deficiency of the written examination and closed system, let the students fully elaborate their own unique point of view. This evaluation method is conducive to the cultivation of students' thinking ability and innovative ability, also in line with the requirements of quality education.

\section{Conclusion}

In the implementation of the teaching evaluation, the evaluation activities should be regarded as an indispensable part of daily teaching, which is not divorced from the teaching practice, but also can fully mobilize and give full play to the initiative of teaching and learning in order to be more objective and comprehensive to examine students' language using ability and learning ability. Of course, the establishment of a scientific and comprehensive evaluation system of Higher Vocational English teaching needs a process, hoping that through the common research and discussion, we can walk out of a way that is in line with the characteristics of Higher Vocational English teaching evaluation.

\section{References}

[1] Huang Yiyun. Construction of Higher Vocational English Evaluation System Based on vocational ability training [J]. Journal of Shaoguan University, 2011,03:177-180.

[2] Chen Xiuli. Construction of multiple evaluation system of English Teaching in Higher 
Vocational College [J]. Journal of Shanxi University of Finance and Economics, 2011, S2:83-84.

[3] Wang Zaili. Construction of the multiple evaluation system of Higher Vocational College English [J]. Chinese adult education, 2011,16:164-166.

[4] Chen Xiaojin, Han Ling. Service for professional English evaluation system reform in Higher Vocational Colleges [J]. Journal of Wuhan Institute of Shipbuilding Technology, 2009,01:131-134.

[5] Shao Hongwan. A combination of formative assessment and final evaluation in Higher Vocational College English multiple evaluation system [J]. Journal of Southwest Agricultural University (SOCIAL SCIENCE EDITION), 2009,06:229-230. 